\title{
Um retrato da psicóloga brasileira
}

\author{
Quem é a psicóloga brasileira? \\ Mulher, psicologia e trabalho.
}

LHULLIER, Louise A. (Org.).

Brasília: Conselho Federal de Psicologia, 2013. $158 \mathrm{p}$.

Organizado por Louise A. Lhullier, doutora em psicologia, psicanalista, professora colaboradora do Programa de Pós-Graduação em Psicologia na Universidade Federal de Santa Catarina, o livro Quem é a psicóloga brasileira? Mulher, psicologia e trabalho é uma coletânea de textos que elucida a relação entre as mulheres e a psicologia, como profissão e como ciência

A coletânea possui cinco capítulos, que discutem os dados de uma pesquisa quantitativa subsidiada pelo Conselho Federal de Psicologia (CFP), em 2012. O estudo foi realizado pelo Instituto ETHOS, coordenado pela organizadora da coletânea, e foram pesquisadas 1.331 psicólogas de todo Brasil. Um dos principais dados obtidos foi o de que $88 \%$ dos 232 mil profissionais da psicologia em exercício no país são mulheres. Além dos dados da pesquisa analisados nos cinco capítulos inicias, os apêndices I e ll do livro revelam informações metodológicas da pesquisa.

Na introdução da coletânea, Lhullier explica que foi demandado aos/às autores/as da coletânea que escrevessem sobre as informações quantitativas obtidas pelo CFP nos Conselhos Regionais. Não tendo como objetivo o consenso entre os/as autores/as, cada capítulo apresenta uma leitura diferenciada dos dados fornecidos pela pesquisa feita, muitas vezes tratando de maneira focalizada apenas um aspecto relevante das informações, apresentando análises, por vezes parciais e específicas, dos dados.

No primeiro capítulo, intitulado "As psicólogas brasileiras: levantando a ponta do véu", escrito pela própria Lhullier em conjunto com a estatística pós-graduada em Marketing Jéssica J. Roslindo, as autoras apresentam os dados da pesquisa, que traçam o perfil das profissionais psicólogas brasileiras. O trabalho das psicólogas foi analisado por elas através da eleição de duas categorias: atuação como psicóloga e área de ałuação como psicóloga.
Na primeira pesquisa, as respostas possíveis eram: "exclusivamente psicóloga", "não exerce, mas pretende exercer", "exerce, mas não é sua principal atividade", "é sua principal atividade, mas não a única", "já exerceu, mas não mais", "não exerce e não pretende exercer", "não exerce nenhuma atividade remunerada". Os principais resultados revelados por esta categoria mostram que mais da metade das psicólogas exercem a profissão de forma exclusiva, enquanto um sexto delas não exerce a profissão, mas pretende fazê-lo.

Na segunda categoria, as alternativas eram: "saúde", "trabalho/organizacional/ RH", "educação", "assistência social", "mobilidade urbana e trânsito/transportes", "mundo jurídico", "clínica", "comunidade/projetos sociais/ONGs", "direitos humanos", "comunicação social", "formação", "questões de gênero", "outras respostas". A área de atuação mais prevalente foi a da saúde, concentrando quase metade das psicólogas, seguida da atuação em organizações e na educação, revelando que as três grandes áreas de atuação da psicologia (clínica, organizacional, educação) continuam sendo as que concentram maior quantidade de profissionais. Ainda nessa parte, há também dados sobre o local de trabalho e o número de horas semanais destinadas à atividade principal como psicóloga.

A renda e o poder aquisitivo foram analisados de duas maneiras: através da parcela dos rendimentos provenientes da atividade como psicóloga e dos rendimentos provenientes da psicologia (em salários mínimos). Entre as participantes da pesquisa, $62 \%$ têm entre $90 \%$ e $100 \%$ de sua remuneração mensal proveniente de suas atividades como psicólogas, e a maior parte dos rendimentos mensais provenientes da psicologia enquadra-se no intervalo de 3 a 10 salários mínimos.

A análise sobre formação complementar e pós-graduação gerou uma vasta gama de informações, começando pelos tipos de titulação encontrados: mestre, especialista e doutor, Os dados revelam que o título prevalente é o de especialista, contabilizando $45 \%$ da amostra, e que apenas $7 \%$ das psicólogas possuem mestrado ou formação superior ao mestrado. $O$ texto ainda informa estatísticas sobre a área em que as psicólogas possuem o título de pósgraduação e a área em que estavam fazendo formação complementar no momento da reali- 
zação da pesquisa. O estudo também apresentou um levantamento de quais os/as principais autores/as de referência na prática profissiona dessas psicólogas, constatando uma presença ainda forte de Sigmund Freud, que somou 28\% das respostas, seguido por Carl Gustav Jung (7\%), Carl Rogers (6\%) e B. F. Skinner (5\%).

Além de estatísticas mais ligadas à profissão, o texto contemplou dados de perfil sociode mográfico, que incluíram: a faixa etária das profissionais $-57 \%$ com idades entre 30 e 49 anos -; a cor ou a raça declarada por elas $67 \%$ brancas, $25 \%$ pardas, $3 \%$ negras, $3 \%$ amarelas e apenas $1 \%$ indígenas -, dados estes que revelam como a questão racial do acesso ao ensino superior ainda afeta fortemente a profissão; também abordou questões como relacionamentos, a média de filhos entre as profissionais, o modo como trabalho doméstico é gerenciado por elas, o cuidado de si, as experiências pessoais marcantes - como casos de violência sofrida - $e$ o contato com o CFP. Os dados referentes a essas últimas temáticas parecem ser os que proporcionaram um caráter diferencial para o referido estudo, pois ampliaram a possibilidade de criação de um perfil das psicólogas brasileiras para além dos dados estritamente profissionais, revelando um universo mais complexo.

O fato de cerca de $89 \%$ da categoria ser composta por mulheres leva-nos a questionar as causas dessa esmagadora maioria de profissionais na psicologia e a problematizar as divisões entre trabalho feminino e trabalho masculino, o que é contemplado pelo segundo capítulo da coletânea.

Intitulado "Trabalho feminino, trabalho masculino: desdobramentos da divisão sexual do trabalho", esse capítulo foi escrito pela doutora em teoria psicanalítica Rita Flores Müller e a graduanda em psicologia Geni Núñes. As autoras refletem sobre a divisão sexual das profissões, usando os estereótipos do homem engenheiro e da mulher psicóloga para problematizar a definição de profissões como femininas ou masculinas. Para responder a esse questionamento, recorrem ao efeito de naturalização da suposta fragilidade do corpo da mulher e da força concentrada no corpo masculino, resultando na produção dessas diferenciações limitadoras com efeitos socioculturais.

A naturalização é pensada como o processo pelo qual se transforma algo que é cultural em uma norma, e essa norma passa a ser compreendida pelas pessoas envolvidas nessa cultura como algo intrínseco ao ser, que sempre foi assim e sempre será. A questão levantada pelas autoras é a arbitrariedade desse processo e sua possível desconstrução. Ressaltam, também, a produção histórica da diferenciação entre o espaço público (espaço da polííica, da ação, da construção, do progresso científico e tecnológico), o papel dos movimentos e o espaço privado (do cuidado, da privacidade, da vida enclausurada, da manutenção da vida), onde as mulheres foram confinadas. A presença massiva de mulheres na psicologia parece relacionarse intimamente com a questão essencial do privativo da vida psicológica e dos cuidados, assim como o caráter privado da profissão.

Outro ponto discutido pelas autoras é concepção da teórica feminista Donna Haraway que acredita que a distribuição simbólica do público e do privado sustenta as relações hierárquicas entre homens e mulheres, criando padrões sexuais acríticos. A dicotomia de gênero ainda é muito presente principalmente no campo do trabalho, mas a barreira da produção do saber/fazer, embora rígida, não é intransponível. Os esforços militantes têm contribuído historicamente para a transformação de espaços, antes tidos como naturalizados, por isso a tendência, cada vez mais, de essa divisão ser atenuada.

"A feminização da profissão e a presença das mulheres na psicologia" é o título do terceiro capítulo, que também foi escrito por Rita Flores Müller, dessa vez, em conjunto com a graduanda em psicologia Bruna Camillo Bonassi. As autoras realizam um mapeamento sobre a feminização da psicologia em outros países. Segundo os dados apresentados, os Estados Unidos e o Canadá possuem a maior quantidade de informações disponibilizadas acerca da presença das mulheres na psicologia. Tais dados revelam que houve uma mudança significativa na American Psychological Association (APA) quando mulheres, minoria nos altos cargos da instituição nos meados da década de 1970, passaram a ocupar grande parte desses cargos na década de 90. Em contraste com EUA e Canadá, a América Latina na década de 70 já apresentava até $85 \%$ de mulheres nos cargos das associações de psicologia de alguns países. Duas hipóteses são levantadas para explicar tais fatos: a imagem da profissão feminina da psicologia em países latino-americanos e a tendência dos homens latinos a procurarem profissões tradicionalmente masculinas e a de que a renda advinda da ałuação na psicologia não seria suficiente para prover uma família, afastando homens ligados a características da masculinidade hegemônica desse campo de trabalho. As autoras também trazem dados da Europa, África e Ásia. Fica clara 
a escassez de produção sobre as mulheres na psicologia.

A doutora em psicologia Maria Fernanda Diogo e a doutora Maria Chalfin Coutinho são as autoras do quarto capítulo, "Ser psicóloga no Brasil: entre o exercício profissional e a realização de atividades domésticas e de cuidado não remuneradas". Elas recorrem à informação da pesquisa do CFP de que $69 \%$ das psicólogas brasileiras trabalham jornadas menores que 40 horas semanais, e a maioria delas exerce sua profissão em consultórios particulares, um tipo de inserção que privilegia a flexibilização da jornada de trabalho. Essa flexibilidade, aliada ao exercício prioritário de jornadas parciais, pode favorecer a harmonização dos fóruns domésticos e laborais, e parece que esse fato é visto pelas mulheres como um grande atrativo da profissão.

A pesquisa do CFP também revelou que cerca de $53 \%$ das psicólogas moram com seus parceiros e $41 \%$ residem com os filhos/as e/ou enteados/as. $O$ percentual de psicólogas que possuem filhos/as e/ou enteados/as é de $59 \%$ contra apenas $41 \%$ para os psicólogos, e, enquanto $46 \%$ delas dedicam 4 horas ou mais no cuidado diário com filhos/as ou enteados/as, apenas $24 \%$ deles possuem jornadas semelhantes. Em relação ao trabalho doméstico, as mulheres dedicam mais tempo a esses afazeres do que aos relacionados à profissão: $32 \%$ das psicólogas dedicam três ou mais horas diárias aos trabalhos domésticos, contra $15 \%$ dos psicólogos; $18 \%$ dos psicólogos não fazem trabalhos domésticos ante $12 \%$ das psicólogas. As autoras concluíram, baseadas nesses dados, que a dupla jornada de trabalho feminina atravessou a inserção laboral das participantes da pesquisa. Também defendem que essa condição prejudica a emancipação feminina e só seria sanada com uma divisão igualitária do trabalho doméstico, no cuidado com os membros da família, e o aumento de serviços assistenciais às famílias.

O último capítulo da coletânea, "As psicólogas e as mutações no mundo do trabalho", fol escrito pelos doutores Oswaldo Yamamoto e Isabel de Oliveira, em conjunto com a doutoranda em psicologia Ana Ludmila Costa, e trata dos efeitos que uma crise do capital, responsável por uma subproletarização da população brasileira, com a consequente precarização de seu trabalho e expansão dos assalariados médios, sobretudo do setor de serviços. Esses fatores evidenciam a precarização de um trabalho que implica grande esforço de especialização - a qual não se reflete em um salário médio alto, ficando entre 5 e 10 salários mínimos. A associação histórica da psicologia com o cuidado também parece estar relacionada com os salários mais baixos, assim como o trabalho parcial e/ou voluntário, apropriando práticas de autoconhecimento e de ajuda ao outro, fazendo da profissional da psicologia uma pessoa que nem sempre consegue ser a responsável principal pela renda familiar. Associase a isso também o fato de os vínculos empregatícios ocorrerem de forma parcial ou em baixas cargas horárias.

A coletânea organizada por Louise Lhullier provoca importantes reflexões sobre a atuação das profissionais psicólogas, os discursos sobre a profissão e os impactos da inserção dessas mulheres no mundo do trabalho contemporâneo. O estopim desse livro foram os dados da pesquisa do Conselho Federal de Psicologia, que nos fornecem um retrato bastante amplo da a psicóloga brasileira: representa $89 \%$ da categoria, é uma mulher que tem dupla jornada de trabalho, remuneração inadequada e relegada ao campo do privado e dos cuidados. O privado é geralmente compreendido como inferior ao público, e isso acaba se refletindo na imagem que a psicologia tem, de ciência inferior. A psicóloga brasileira é também uma mulher que questiona a divisão sexual do trabalho, a precarização e a baixa remuneração; que milita pelo reconhecimento da profissão, pela redistribuição igualitária das tarefas domésticas e pela emancipação das mulheres.

O campo da psicologia está passando por um momento importante de quebra de estereótipos, de discursos naturalizados e acríticos e de busca pelo reconhecimento da profissão. Essas questões, mesmo tendo sido abordadas na coletânea, poderiam ter tido um maior espaço e aprofundamento na obra; mas, sem dúvida, o livro contém informações, reflexões e questionamentos essenciais para embasar qualquer trabalho que objetive discutir o campo profissional da psicologia numa perspectiva de gênero.

Livia Espíndola Monte Universidade Federal de Santa Catarina 